\title{
Recurrence of duodenal ulcer pain after treatment with cimetidine for four and eight weeks
}

\author{
S J RUNE*, J GREIBE, K-M MøLLMAN, J RASK MADSEN, I RAHBEK, \\ L WILLUMSEN, AND H R WULFF
}

From the Medical Department F, Glostrup University Hospital, Glostrup, Denmark, and Medical Department $C$, Herlev University Hospital, Herlev, Denmark

SUMmARY This double-blind controlled trial compares the relapse rate in 19 duodenal ulcer patients who received cimetidine for eight weeks with that in 19 patients who received cimetidine for four weeks and inactive tablets for four weeks. Only patients who became symptom-free during the initial four weeks' treatment with cimetidine were included. The median period of remission after withdrawal of cimetidine was 50 days in patients treated with cimetidine for eight weeks and 76 days in patients treated with cimetidine for four weeks $(P>0 \cdot 10)$. Six months after withdrawal of cimetidine 15 relapses had occurred in both groups. It is concluded that patients who become symptom-free during four weeks' cimetidine treatment do not benefit by continuation of treatment for another four weeks.

The effect of short-term treatment with cimetidine in duodenal ulcer disease is now well established, but unfortunately the relapse rate is high when treatment is stopped. Patients who respond quickly to the drug are usually only treated for four weeks, and there was a possibility that treatment for a longer period of time would delay subsequent relapses. We therefore decided to do a controlled study of the relapse rate in duodenal ulcer patients who had become symptom-free during four weeks' treatment and then continued on either cimetidine or placebo for another period of four weeks. The trial was designed to imitate clinical practice outside specialised hospital departments; consequently a radiological diagnosis was accepted as sufficient evidence of duodenal ulcer disease, and a relapse was recorded when ulcer symptoms recurred.

\section{Methods}

\section{PATIENTS}

Sixty consecutive patients who fulfilled the following criteria were admitted: (1) barium meal examination showing duodenal crater or deformity of duodenal cap; (2) epigastric pain on least at four days during

*Address for correspondence: S J Rune, Medical Department F, Glostrup University Hospital, DK 2600 Glostrup, Denmark.

Received for publication 17 September 1979 the preceding week; (3) no previous gastric or biliary surgery; (4) no cimetidine treatment during the preceding two months. Patients who previously had taken part in a controlled study of maintenance treatment with cimetidine were also excluded; (5) no renal, hepatic, or cardiac disease; (6) informed consent. Children below 16 years of age and pregnant or lactating women were excluded. A pentagastrin test was performed in 57 of the 60 patients before treatment, and laboratory screening for sideeffects was done as previously described. ${ }^{1}$

All patients received cimetidine tablets $(200 \mathrm{mg})$ and were instructed to take one tablet three times daily after meals and two tablets at bedtime. Other ulcer treatment, including antacids, was stopped. The patients were seen after four weeks, and those who had had no symptoms during the preceding five days were randomly allocated to continued cimetidine treatment or to placebo treatment (inactive tablets identical in appearance). Four weeks later (or before, if a relapse had occurred) treatment was stopped, and from then on the patients were seen every four weeks for six months or until they relapsed. A relapse was recorded when a patient had suffered moderate or severe pain on at least five days within a fortnight. Patients who relapsed received open cimetidine treatment.

The study was double-blind and the code remained closed until all patients had completed the trial. 
Table Comparison of cimetidine and placebo groups

\begin{tabular}{|c|c|c|c|}
\hline & $\begin{array}{l}\text { Cimetidine } \\
\text { group }\end{array}$ & $\begin{array}{l}\text { Placebo } \\
\text { group }\end{array}$ & Significance \\
\hline $\begin{array}{l}\text { Sex ratio: men: women } \\
\text { Mean age in years (range) } \\
\text { Mean duration of ulcer } \\
\text { history in years (range) }\end{array}$ & $\begin{array}{l}13: 6 \\
46(33-72)\end{array}$ & $\begin{array}{l}11: 8 \\
47(20-68) \\
9(1-50)\end{array}$ & $\begin{array}{l}\text { NS } \\
\text { NS } \\
\text { NS }\end{array}$ \\
\hline
\end{tabular}

NS: non-significant ( $P>0.05$, Mann-Whitney test).

\section{Results}

Forty-five of the 60 patients were symptom-free after four weeks' cimetidine treatment. Of these 25 were allocated to cimetidine and 20 to placebo. Six patients from the cimetidine group were withdrawn for the following reasons: two failed to visit the outpatient department after cessation of treatment, one was lost to the trial due to faulty organisation on our part, one reduced the dose on his own account, one complained of vomiting, and one was later found to have a gastrinoma. One patient from the placebo group also failed to attend the outpatient department. Of the remaining 38 patients 19 received cimetidine for eight weeks, whereas 19 received cimetidine for four weeks and placebo for four weeks. The two groups were found to be comparable (Table).

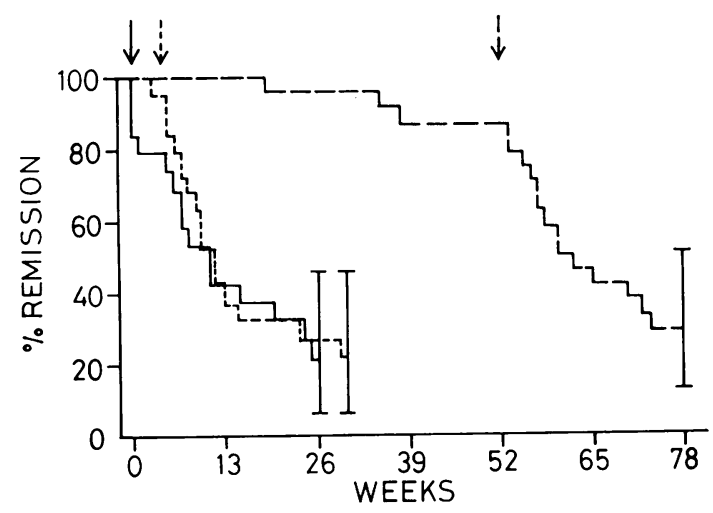

Figure The curves show the occurrence of relapses in three groups of patients (ordinate axis: per cent of patients still in remission). _- relapses among 19 patients who at week 0 had received four weeks' cimetidine treatment and from week 0 to four received plucebo treatment. - . - - relapses; among 19 patients who at week 0 had received four weeks' cimetidine treatment and from week 0 to four received cimetidine for an additional pertod of four weeks. - _ - ; relapses among 29 patients who received maintenance treatment with cimetidine from week 0 to week $52 .^{3}$ The arrows indicate when cimetidine was withdrawn. The $95 \%$ confidence limits of the remission rates six months after withdrawal are shown.
The Figure shows the occurrence of relapses after the first treatment period-that is, from the day when the patients were allocated to an additional four week course of cimetidine or to placebo. All but one of the patients in the cimetidine group remained in remission during the second treatment period, whereas four patients relapsed in the placebo group. The patients in the cimetidine group, however, soon began to relapse when treatment was stopped, and six months after the withdrawal of cimetidine 15 relapses had occurred in both groups. Consequently, the rate of continued remission six months after withdrawal of cimetidine was $21 \%$ (95\% confidence interval: $6-46 \%$ ) in both groups. The median period of remission after withdrawal of cimetidine was 50 days in the cimetidine group and 76 days in the placebo group ( $P>0 \cdot 10$, MannWhitney test).

The duration of the remission was not significantly correlated with the length of ulcer history $\left(R_{s}=0.01\right)$, or with the basal acid output $\left(R_{s}=-0 \cdot 10\right)$ or with the peak acid output $\left(R_{s}=-0.31\right)$ (Spearman tests, $P>0.05$ ). No unexpected symptoms, signs, or laboratory findings were observed (apart from the patient excluded because of vomiting).

\section{Discussion}

Ippoliti et al. ${ }^{2}$ subjected their patients to duodenoscopy and found that some patients became symptom-free during four weeks' treatment in spite of the fact that their ulcer had not healed. It was suspected that such patients were particularly liable to relapse and that prolonged treatment might ensure the healing of their ulcers. This study, however, reveals that nothing is gained by four weeks' additional treatment, a finding which suggests that remission induced by cimetidine continues after withdrawal of the drug.

In a previous trial ${ }^{3}$ we studied the occurrence of relapses after maintenance with cimetidine $0.8 \mathrm{~g}$ per day for 52 weeks, and the results of that study are also shown in the Figure; they differ slightly from those previously published as all patients have now been followed up for six months after withdrawal of treatment. It is seen that the relapse curve closely resembles those after four and eight weeks' treatment, and, in spite of some differences between the protocols of the two trials, this resemblance suggests that the relapse rate is uninfluenced by the duration of treatment.

Patients who repeatedly relapse quickly after a course of cimetidine are usually referred to surgical treatment, and such patients have gained little by 
the introduction of cimetidine. It would therefore be useful to be able to predict the duration of the remission, and recently it has been reported ${ }^{4}$ that patients with a short history were less liable to relapse quickly than patients with a long history. In this study the duration of the remission was found to be correlated neither with the length of history nor with the acid production.

This study was supported by Grant 512-10171 from the Danish Medical Research Council. Cimetidine and placebo tablets were kindly provided by Smith Kline \& French, Welwyn Garden City.
References

${ }^{1}$ Gudmand-Høyer E, Frost F, Birger Jensen K, et al. A pragmatic trial of cimetidine in duodenal ulcer patients. Scand J Gastroentol 1977; 12: 611-3.

${ }^{2}$ Ippoliti AF, Sturdevant RAL, Isenberg JI, et al. Cimetidine versus intensive antacid therapy for duodenal ulcer. Gastroenterology 1978; 74: 393-5.

${ }^{3}$ Gudmand-Høyer E, Birger Jensen K, Krag E, et al. Prophylactic effect of cimetidine in duodenal ulcer disease. Br Med J 1978; 1 : 1095-7.

${ }^{4}$ Ippoliti AF, Elashoff J, Cooney C, Sturdevant R, Isenberg J. Duodenal ulcer relapse after cimetidine withdrawal Gastroenterology 1978; 74: 1047. 